\section{Case Reports in Ophthalmology}

Case Rep Ophthalmol 2017;8:321-325

DOI: $10.1159 / 000477159$ Published onlıne: IVlay 29, 2017
(C) 2017 The Author(s)

Published by S. Karger AG, Basel www.karger.com/cop

This article is licensed under the Creative Commons Attribution-NonCommercial 4.0 International License (CC BY-NC) (http://www.karger.com/Services/OpenAccessLicense). Usage and distribution for commercial purposes requires written permission.

\title{
Rapid Cataract Progression after Nd:YAG Vitreolysis for Vitreous Floaters: A Case Report and Literature Review
}

\author{
I-Ting Sun $^{a} \quad$ Tsung-Han Lee $^{b} \quad$ Chih-Hsin Chen ${ }^{b}$ \\ ${ }^{a}$ Department of Ophthalmology, E-DA Hospital, I-Shou University, Kaohsiung, Taiwan; \\ ${ }^{b}$ Department of Ophthalmology, Chang Gung Memorial Hospital Kaohsiung Medical \\ Center, Chang Gung University College of Medicine, Kaohsiung, Taiwan
}

\section{Keywords}

$\mathrm{Nd}$ :YAG vitreolysis · Cataract · Vitreous floaters

\begin{abstract}
Purpose: We report a case of rapid cataract progression after Nd:YAG vitreolysis for vitreous floaters. Case Report: A 55-year-old man presented with acute onset of blurred vision following Nd:YAG vitreolysis for symptomatic floaters in the left eye. His initial best corrected visual acuity (BCVA) was 20/1,000 in the left eye. Ocular examinations showed frost-like opacities of the lens and a suspected break of the posterior capsule in the left eye. There were no detectable retinal lesions. Cataract surgery was then arranged. Posterior capsular rupture and vitreous loss occurred during surgery, which required a subsequent pars plana vitrectomy. After the surgery, BCVA in the left eye gradually improved to 20/20 and was maintained during a 1-year follow-up period. Conclusion: Crystalline lens injuries and rapid cataract progression may occur following Nd:YAG vitreolysis. While dealing with this type of complicated cataract, clinicians should be aware of the possibility of posterior lens capsule rupture during surgery and the need for combined vitrectomy.
\end{abstract}




\section{Introduction}

In most clinical settings, vitreous floaters are not considered as an intolerable clinical problem that needs specific intervention. However, recent studies have shown that floaters may become a serious medical condition and cause a significant negative impact on the quality of life in some patients, for whom interventions are necessary to get rid of the symptoms $[1,2]$.

Nd:YAG laser vitreolysis, one type of treatment for symptomatic floaters, has moderate success rates and is regarded as a relatively safe procedure with minimal complications [3]. Complications reported for Nd:YAG laser vitreolysis include increased intraocular pressure (IOP), chorioretinal bleeding, retinal holes, vitreous hemorrhage, cystoid macular edema, and localized retinal swelling [3-6]. However, there are limited reports indicating that $\mathrm{Nd}$ :YAG laser vitreolysis may cause a crystalline lens injury. Here, we report a case with rapid progressing cataract (posterior subcapsular type) after Nd:YAG vitreolysis for vitreous floaters.

\section{Case Report}

A 55-year-old man presented to our clinic with acute onset of blurred vision in his left eye for 2 days. This symptom occurred just after he received Nd:YAG vitreolysis for vitreous floaters in the left eye at a local clinic. He had no history of ocular trauma and retinal diseases; he had not undergone prior ocular surgeries. His best corrected visual acuity (BCVA) was $20 / 1,000$ at the initial evaluation. IOPs were normal. Retroillumination by a slit-lamp examination revealed frost-like opacities over the back surface of the lens and a suspected break of the posterior capsule at the superior-temporal quadrant of the lens in the left eye (Fig. 1). In addition, a dot vitreous opacity was found behind the lens of the left eye and was located within the distance of the width of the lens. A funduscopic examination revealed a normal retina without detectable retinal lesions or macular edema in both eyes.

Cataract surgery was performed in the patient's left eye for symptomatic cataract. During the surgery, posterior capsule rupture and vitreous loss were encountered, and an anterior vitrectomy was also performed. A posterior-chamber intraocular lens was implanted in the sulcus over the intact capsulorhexis.

After the surgery, BCVA in the left eye was improved to 20/50. However, the patient complained about increased vitreous floaters in his left eye. Since elevated IOP was also noted, antiglaucoma medications with Combigan ${ }^{\circledR}$ (brimonidine $0.2 \%+$ timolol $0.5 \%$ ) and Xalatan $^{\circledR}$ (latanoprost $0.005 \%$ ) were prescribed. During ocular examinations, some inferior vitreous opacities were found, which were thought to be the residual cortical materials from the previous cataract surgery, causing inflammation, elevated IOP, and progressive symptomatic floaters. After a 1-week treatment with antiglaucoma medications, IOP was maintained at normal levels in the left eye. A subsequent pars plana vitrectomy (PPV) was performed to remove the residual cortical materials. After the surgery, his symptoms were relieved and the intraocular lens was well centered in the sulcus over the intact capsulorhexis (Fig. 2). His BCVA in the left eye gradually improved to $20 / 20$ and was maintained well during a 1-year follow-up period. 


\section{Case Reports in Ophthalmology}

\begin{tabular}{l|l}
\hline Case Rep Ophthalmol 2017;8:321-325 \\
\hline DOI: 10.1159/000477159 & $\begin{array}{l}\text { @ 2017 The Author(s). Published by S. Karger AG, Basel } \\
\text { www.karger.com/cop }\end{array}$ \\
\hline
\end{tabular}

Sun et al.: Rapid Cataract Progression after Nd:YAG Vitreolysis for Vitreous Floaters: A Case Report and Literature Review

\section{Discussion}

Vitreous floaters are most commonly caused by degenerative changes in the vitreous body, such as vitreous syneresis and posterior vitreous detachment. Floaters can also arise from other ocular conditions, including asteroid hyalosis, vitreous hemorrhage, retinal tears, retinal detachments, endophthalmitis, and previous intermediate or posterior uveitis. A careful and thorough ocular examination should be performed in patients complaining of floaters, since pathological floaters might be reversible if underlying causes are properly treated. Vitreous floaters caused by degenerative changes are usually managed conservatively. However, for patients with persistent and symptomatic floaters that influence their quality of life, therapeutic interventions should be considered. In the literature, several treatment modalities have been described to manage symptomatic floaters, including Nd:YAG laser and PPV [3-8].

Nd:YAG laser treatment is more commonly used for posterior capsulotomy following cataract extraction and is less frequently used for vitreolysis. Several studies have reported the use of Nd:YAG laser for vitreolysis. A study by Tsai et al. [8] reported the use of Nd:YAG laser in 15 patients with vitreous floaters, all of whom showed complete resolution of symptoms after the treatment. There were no intraoperative or postoperative complications noted during the follow-up period of $>12$ months. However, in a study by Delaney et al. [3] that compared Nd:YAG vitreolysis and PPV for floaters, only 15 out of 39 eyes (38.5\%) with vitreous floaters showed a symptomatic improvement after Nd:YAG laser treatment and none of them showed complete resolution of symptoms. Furthermore, there were no complications reported after the follow-up period of 14.7 months. Fourteen out of 15 eyes (93.3\%) treated with PPV (4 eyes received primary PPV, while 11 eyes received secondary PPV following failure of Nd:YAG vitreolysis) had full resolution of symptoms. However, 1 of these 15 eyes developed postoperative retinal detachment after the surgery [3]. In a study performed by Schulz-Key et al. [7] that reported the long-term outcome of PPV for vitreous floaters, 4 of 73 eyes (5.5\%) developed retinal detachment during the follow-up period of 24-44 months. Accordingly, Nd:YAG vitreolysis, though only moderately effective, is safer than PPV and should be considered as a primary treatment for symptomatic vitreous floaters, as it reduces the number of patients requiring more extensive vitreous surgery.

There have been few studies reporting the complications following treatment with Nd:YAG vitreolysis. A study by Little and Jack [6] used an Nd:YAG laser to cut vitreoretinal bands and membranes in 16 eyes and to clear vitreous floaters in 25 eyes. Complications following the procedure included focal posterior capsular opacities in 5 eyes, minor retinal hemorrhage $(<300 \mu \mathrm{m})$ in 4 eyes, and retinal breaks with detachment in 1 eye. In another study by Tassignon et al. [9], out of the 72 eyes treated with Nd:YAG vitreolysis, 2 eyes suffered from lens damage with development of cataracts, and 1 eye had retinal detachment following laser treatment. The development of cataracts seems to result from an inadvertent delivery of the laser power anterior to the designated target in the vitreous. Previous studies have indicated that complications may arise when an Nd:YAG laser is used within 2-4 mm of the crystalline lens or retina $[10,11]$. In our study, we suggested that the occurrence of posterior capsular opacities following Nd:YAG vitreolysis was caused by the inadequate distance of the focus from the crystalline lens when applying laser therapy. The complication of lens damage resulted in the development of secondary cataract that profoundly deteriorated the patient's vision and resulted in further surgical management. However, unlike the usual phacoemulsification lens extraction, the prior trauma to the posterior lens surface was hard to evaluate preoperatively; hence, it resulted in a disastrous posterior capsular rupture and 
vitreous loss. Despite performing an anterior vitrectomy and a successful intraocular lens implantation in the ciliary sulcus, secondary PPV was necessitated by the postoperative adverse outcomes, such as abnormal IOP and corneal edema.

\section{Conclusion}

Although Nd:YAG vitreolysis has been reported as an effective and less invasive treatment for symptomatic vitreous floaters, it should be used carefully, especially in phakic eyes. Crystalline lens injuries and rapid cataract progression may occur following Nd:YAG vitreolysis. While dealing with this type of complicated cataract, we should be aware of the possibility of posterior lens capsule rupture during surgery and the need for combined vitrectomy. Further prospective studies are necessary to evaluate the efficacy and safety of Nd:YAG vitreolysis.

\section{Statement of Ethics}

This case study has been approved by the Ethics Committee of Chang Gung Memorial Hospital Kaohsiung Medical Center, Chang Gung University College of Medicine, Kaohsiung, Taiwan.

\section{Disclosure Statement}

There are no conflicts of interest to report.

\section{References}

1 Wagle AM, Lim WY, Yap TP, Neelam K, Au Eong KG: Utility values associated with vitreous floaters. Am J Ophthalmol 2011;152:60-65.

2 Webb BF, Webb JR, Schroeder MC, North CS: Prevalence of vitreous floaters in a community sample of smartphone users. Int J Ophthalmol 2013;6:402-405.

3 Delaney YM, Oyinloye A, Benjamin L: Nd:YAG vitreolysis and pars plana vitrectomy: surgical treatment for vitreous floaters. Eye 2002;16:21-26.

-4 Aron-Rosa D, Greenspan DA: Neodymium:YAG laser vitreolysis. Int Ophthalmol Clin 1985;25:125-134.

5 Fankhauser F, Kwasniewska S, Van Der Zypen E: Vitreolysis with the Q-switched laser. Arch Ophthalmol 1985;103:1166-1171.

-6 Little HL, Jack RL: Q-switched neodymium: YAG laser surgery of the vitreous. Graefes Arch Clin Exp Ophthalmol 1986;224:240-246.

-7 Schulz-Key S, Carlsson JO, Crafoord S: Longterm follow-up of pars plana vitrectomy for vitreous floaters: complications, outcomes and patient satisfaction. Acta Ophthalmol 2011;89:159-165.

-8 Tsai WF, Chen YC, Su CY: Treatment of vitreous floaters with neodymium YAG laser. Br J Ophthalmol 1993;77:485-488.

-9 Tassignon MJ, Kreissig I, Stempels N, Brihaye M: Indications for Q-switched and mode-locked Nd:YAG lasers in vitreoretinal pathology. Eur J Ophthalmol 1991;1:123-130.

10 Bonner RF, Meyers SM, Gaasterland DE: Threshold for retinal damage associated with the use of highpower neodymium-YAG lasers in the vitreous. Am J Ophthalmol 1983;96:153-159.

11 Milston R, Madigan MC, Sebag J: Vitreous floaters: etiology, diagnostics, and management. Surv Ophthalmol 2016;61:211-227. 
Case Reports in
Ophthalmology

Case Rep Ophthalmol 2017;8:321-325

DOI: $10.1159 / 000477159$

(c) 2017 The Author(s). Published by S. Karger AG, Basel www.karger.com/cop

Sun et al.: Rapid Cataract Progression after Nd:YAG Vitreolysis for Vitreous Floaters: A Case Report and Literature Review

I-Ting Sun and Tsung-Han Lee contributed equally as first authors.

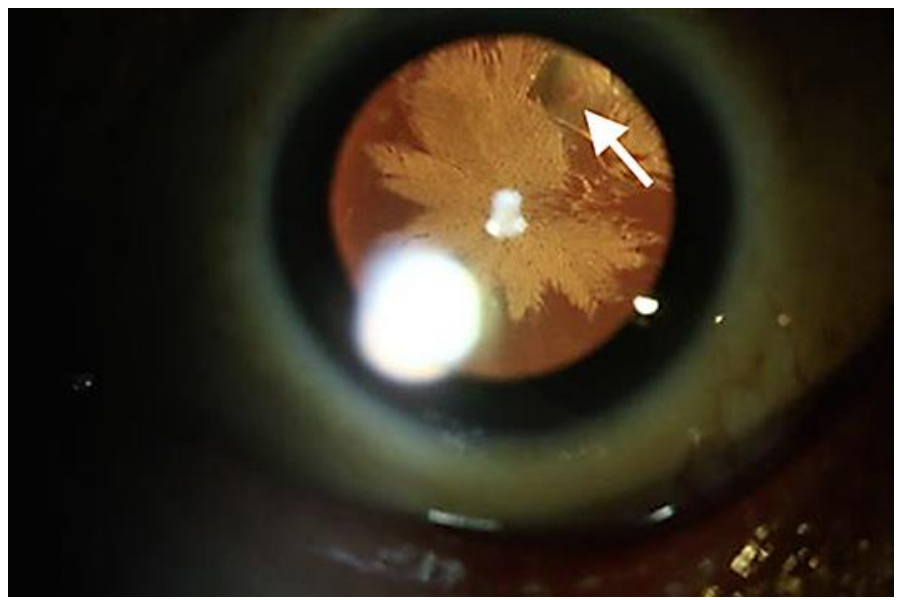

Fig. 1. Frost-like opacities over the back surface of the lens and a suspected break of the posterior capsule (arrow) at the superior-temporal quadrant of the lens in the left eye.

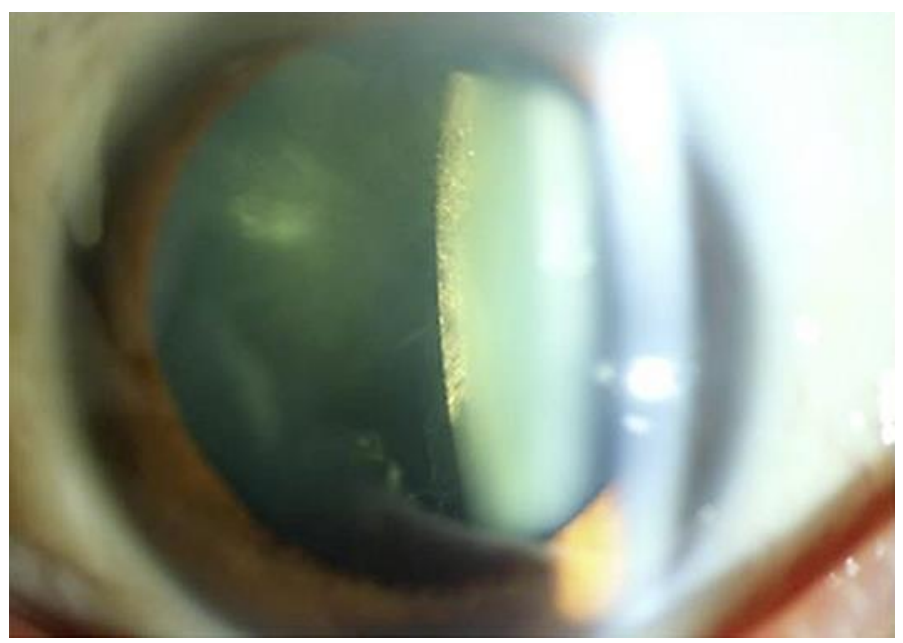

Fig. 2. The intraocular lens was well centered in the sulcus over the intact capsulorhexis. 